\title{
Narratives of family transition during the first year post-head injury: perspectives of the non-injured members
}

\begin{tabular}{|l|l|}
\hline Item type & Article \\
\hline Authors & $\begin{array}{l}\text { Whiffin, Charlotte Jane; Bailey, Christopher; Ellis-Hill, } \\
\text { Caroline; Jarrett, Nicola; Hutchinson, Peter J. }\end{array}$ \\
\hline Citation & $\begin{array}{l}\text { Whiffin, C. J. (2015) 'Narratives of family transition during } \\
\text { the first year post-head injury: perspectives of the non- } \\
\text { injured members', Journal of Advanced Nursing, 71 (4):849 } \\
\text {. DOI: 10.1111/jan.12551 }\end{array}$ \\
\hline DOI & 10.1111/jan.12551 \\
\hline Journal & Journal of Advanced Nursing \\
\hline Rights & Archived with thanks to Journal of Advanced Nursing \\
\hline Downloaded & 9-Apr-2018 10:48:50 \\
\hline Link to item & \\
\hline
\end{tabular}


Title: Narratives of family transition during the first year post-head injury: perspectives of the noninjured members.

Abstract:

Aim: To explore the narratives created by non-injured family members in relation to themselves and their family within the first year after traumatic brain injury.

Background: A traumatic brain injury is a potentially devastating injury. The family responds to this injury by supporting the individual and their recovery. While the perspective of individual family members has been well documented there is growing interest in how the family as a whole makes sense of their experiences and how these experiences change over time.

Design: Longitudinal narrative case-study using unstructured in-depth interviews.

Methods: Data were collected during an 18-month period (August 2009- December 2010). Nine non-injured family members from three families were recruited from an acute neurosurgical ward and individual narrative interviews were held at one, three and 12 months post-injury where participants were asked to talk about their experience of head injury. Analysis was completed on three levels: the individual, the family and between family cases with the aim of identifying a range of interwoven narrative threads.

Results/findings: Five interwoven narratives were identified: trauma, recovery, autobiographical, suffering and family. The narrative approach emphasised that the year post-head injury was a turbulent time forfamilies, who were active agents in the process of change.

Conclusion: This study has shown the importance of listening to people's stories and understanding their journeys irrespective of the injured person's outcome. Change post-TBI is not limited to the injured person: family members need help to understand that they too are changing as a result of their experiences.

Keywords: nurses/nursing, head injury, qualitative, narrative analysis, recovery, rehabilitation, trauma 
Summary Statement

\section{Why is this research needed?}

- Research in traumatic brain injury is predominantly drawn from retrospective and crosssectional studies using heterogeneous samples.

- Family-based investigations frequentlyrecruit single family members and extrapolate their findings to the widerfamily.

- This research contributes to an emerging field of family-based studies through its prospective and longitudinal design and by recruiting several members of the same family.

\section{What are the key findings?}

- Five interrelated narrative threads were found within non-injured family members' stories of the first year post-head injury: trauma, recovery, autobiographical, suffering and family.

- The first year post-head injury is a turbulent time where non-injured family members are active agents in the process of change

- Working with families to val idate their experience, resolve trauma and prevent suffering may go some way to enable family members to positively adjust in the wake of head injury

How should the findings be used to influence policy/practice/ research/ education?

- It is helpful for healthcare practitioners to understand why non-injured members become so embedded within the experience of a relative's head injury.

- Healthcare practitioners should be aware of the impact of their interactions with families and be careful not to invalidate family member stories which can lead to long lasting negative effects

- Where stories between injured and non-injured family members are different there may be an opportunity to help family members share stories and support the whole family come to terms with the effects of head injury 


\section{INTRODUCTION}

Each year millions of people across the world sustain a traumatic brain injury (TBI) (Teasdale 1995). Although the injured person can make a full recovery an extensive range of impairments is common (Wood et al. 2005). The importance of family in the recovery process often means members are relied upon to provide much of the necessary care and support (Gan et al. 2006, Degeneffe \& Olney 2008). A ripple effect is a useful metaphor to conceptual ise the impact this injury has within families. The injury may mark the beginning but as the ripples radiate through family life, head injury has the potential to affect the lives of all family members in a number of complex ways (Gan et al. 2006).

\section{Background}

The impact that TBI has on the non-injured members of a family has been the subject of extensive investigation (Wood et al. 2005, Duff 2006). However, the literature has traditionally presented a one dimensional view of post-injury consequences by concentrating on the presence of stress, depression, anxiety and reduced quality of life (Livingston et al. 1985, Brooks et al. 1986, Brooks et al. 1987, Blake 2008, Schönberger et al. 2010). Although not denying that the presence of such constructs is important following TBI much of the literature does not demonstrate the complexity of how and why the family is so affected (Anderson et al. 2002). Researchers in head injury have therefore turned their attention to broader constructs such as family functioning, which has emerged as a key variable within the literature (Whiffin 2012). Research has identified a correlation between unheal thy family functioning and increased strain and depression and reduced life satisfaction in a range of family members (Anderson et al. 2002, Nabors et al. 2002, Carnes \& Quinn 2005, Gan et al. 2006).

However, research in TBI is predominantly drawn from retrospective and cross-sectional studies using mixed groups of participants varying in time since injury from a few months to several years. In addition family based investigations frequently recruit single family members and extrapolate their findings to the wider family. Where studies do recruit multiple members of the same family they rarely consider how data from the same family compare to each other. The research reported here addresses these limitations and contributes to an emerging field of family based studies within TBI.

\section{Conceptual framework}

An investigation into the family experience of head injury required a flexible approach enabling the family to be conceptualised as a dynamic, individualised and socially constructed system. The constructivist paradigm met these criteria, firmly placing the emphasis of investigation on subjectivity and the value of exploring the difference in people's experiences (Miles and Huberman 1994).

The priorities of the constructivist paradigm are consistent with those of narrative theory and are often used together (Sparkes \& Smith 2008). Bingley et al. (2008) explain that as our normal routine of daily life is disrupted a story of the event is created 'stories, therefore, gain a particular relevance at times of life transition or change, seemingly as a way of 'sense-making' or attempting to reshape and manage the shifting ground of ourlives' (p.655). Embedded within these stories are the materials that the person has used to make sense of their experience.

\section{THE STUDY}

\section{Aim}

The aim of this study was to explore the narratives created by non-injured family members in relation to themselves and their family within the first year after traumatic brain injury to a relative. 


\section{Design}

A longitudinal narrative case study design was utilised enabling each family to be conceptualised as a unique case. Case study methodologyis considered to be commensurate with the ontological assumptions of constructivist research (Appleton 2002) and is described as an 'intensive, holistic description and analysis of a single unit or bounded system' (Merriam, 1998 p.12). Each family unit provided the fundamental boundedness required for case study investigations (Stake 2005).

\section{Participants}

Three family cases were recruited from an acute neurosurgical ward using purposive sampling. A case was defined as a family where a member had sustained $\mathrm{a}$ TBI and met the inclusion/exclusion criteria (Table 1). The family was defined according to the principle that "the family is who they say they are" (Wright and Leahey 2009, p.60), and recruitment to the study was designed to allow families to self-select members for participation who met the inclusion criteria (Table 2). Participants were first approached by the clinical nurse practitioner, those who expressed an interest in taking part completed a reply slip. The lead author $(\mathrm{CW})$ then made contact and introduced themselves and the study.

Table 1: Patient criteria

\begin{tabular}{|c|c|c|c|}
\hline Inclusion Criteria & Rationale & $\begin{array}{l}\text { Exclusion } \\
\text { Criteria }\end{array}$ & Rationale \\
\hline $\begin{array}{l}18 \text { years of age or } \\
\text { above }\end{array}$ & \multirow{3}{*}{$\begin{array}{l}\text { To recruit patients } \\
\text { with similar } \\
\text { journeys through } \\
\text { the healthcare } \\
\text { system who have } \\
\text { access to the } \\
\text { same/ similar } \\
\text { services }\end{array}$} & $\begin{array}{l}\text { Prior head } \\
\text { injury }\end{array}$ & \multirow{5}{*}{$\begin{array}{l}\text { To exclude } \\
\text { cases where } \\
\text { the impact of } \\
\text { TBI would be } \\
\text { difficult to } \\
\text { examine } \\
\text { given the } \\
\text { presence of } \\
\text { otherissues. }\end{array}$} \\
\hline $\begin{array}{l}\text { Moderate- } \\
\text { Severe TBI }\end{array}$ & & $\begin{array}{l}\text { Previous } \\
\text { psychiatric } \\
\text { history }\end{array}$ & \\
\hline $\begin{array}{l}\text { Will potentially } \\
\text { require inpatient } \\
\text { rehabilitation }\end{array}$ & & Dementia & \\
\hline $\begin{array}{l}\text { Within one } \\
\text { month of injury }\end{array}$ & $\begin{array}{l}\text { To examine } \\
\text { experiences of } \\
\text { acute care }\end{array}$ & $\begin{array}{l}\text { Alcohol or } \\
\text { substance } \\
\text { abuse }\end{array}$ & \\
\hline $\begin{array}{l}\text { Admitted to a } \\
\text { ward }\end{array}$ & $\begin{array}{l}\text { To ensure phase } \\
\text { of critical illness } \\
\text { had passed }\end{array}$ & $\begin{array}{l}\text { Living in a } \\
\text { long-term } \\
\text { care facility }\end{array}$ & \\
\hline
\end{tabular}

Table 2: Non-injured family memberinclusion criteria
18 years of age or older
Able to provide informed consent
Informed of the patient's diagnosis
Available to participate in face-to-face interviews

\section{Data collection}

Data were collected using unstructured narrative interviews following an adapted three stage process by Wengraf and Chamberlayne (2006) (Figure 1). This interview was piloted and no changes were necessary. Interviews were completed at the location requested by family members including; a hospital based clinical research facility, their home or place of work. Interview were conducted by the lead author $(\mathrm{CW})$, a senior lecturer and registered nurse with training in interview technique and 
clinical experience of TBI. Nine family members completed a total of 26 interviews (one participant withdrew before the final interview) lasting on average 90 minutes (range 40-137 minutes). Interviews were audio recorded and field notes were maintained.

\section{Figure 1: Interview framework}

\section{Stage One}

Single question to initiate narrative response

"I would like you to think about your (insert relationship)'s injury and what has happened in the time since the injury. Please tell me the story of this injury, all the events and experiences that have been important to you personally. Begin where you like, please take the time you need. I'll listen first, I won't interrupt. I'll just take some notes for after you've finished telling me about your experiences."

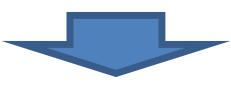

Stage Two

Questions about subjects raised in the same order they were spoken about, using the same language

"When you spoke about feeling angry please can you explain to me what you meant?"

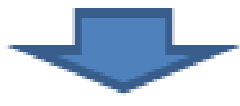

\section{Stage Three}

Pre-designed questions based on relationships, key moments, needs, challenges and perceptions of the future.

(questions not asked if already explored by participant)

\section{Ethical considerations}

Ethical approval for this study was granted by the Ethics Committee in October 2008 (REC Reference Number: 08/H0308/181).

At the start of the study all patients lacked capacity to provide informed consent for their family members to take part. Therefore, the next-of-kin and other family members were approached with written information and given a 48-hour cooling off period. Participation was voluntary and participants could withdraw at any time. When patients regained capacity they were asked about their family member's participation in the study. Each patient agreed and provided written informed consent.

Pseudonyms were used throughout the research and identifying details changed. It was also agreed that the helpline for Headway, a charitable organisation supporting families affected by brain injury, would be available to them as a support mechanism.

\section{Data Analysis}

The data were explored using methods consistent with an in-depth narrative analysis. To this end data were treated holistically to maintain and reconstruct a whole story (Riessman \& Quinney 2005). Data were analysed to examine the 'temporality' of the experience which was considered to be life before TBI, life now and life after. Riessman (2008) stated that 'a good narrative analysis prompts the reader to think beyond the surface of a text, and there is a move towards a broader 
commentary' (p.3). To achieve this data were analysed on three levels, the individual, the family and between cases. This enabled the analysis to move beyond a simple representation of what was said towards a demonstration of how narratives were used to portray the storyteller's biographical sense of self, others and the family system. Informing the analysis was the Life Thread Model (Ellis-Hill et al, 2008) which suggests that people construct their sense of self and well-being through a number of interrelated narrative threads. The interpretation was al so influenced by Gergen and Gergen's (1983) model of narrative direction whereby movement toward or away from a valued goal represents either progressive or regressive narratives, that can be interpreted as hel pful or harmful respectively. Data were coded by $\mathrm{CW}$ and interpretations discussed in doctoral supervision with $\mathrm{CB}$, CEH and NJ.

For a more detailed account of the data analysis process see Whiffin (2012) and Whiffin et al (2014).

\section{Rigour}

A reflexive diary was maintained throughout the research to assist in establishing an audit trail from raw data to findings. In addition, an approach similar to negative case analysis was used whereby data were examined specifically for examples that did not support early interpretations (Creswell 2007). The longitudinal approach enabled clarification of issues and emerging interpretations to be tested with participants. However, stories do not have one interpretation and 'in the final analysis, the work is ours. We have to take responsibility for its truths' (Riessman 1993, p67). Final narratives were therefore considered a co-constructed experience between researcher and participant (Mishler 1995).

\section{Findings}

Between August and December 2009 nine non-injured family members were recruited (Figure 2). Recruiting three cases and a small number of participants facilitated an in-depth inquiry. Two other families were approached but did not meet the inclusion criteria to participate.

Although data were not collected from the brain-injured person it was confirmed from family accounts that all had severe injuries requiring sedation in intensive care and periods of posttraumatic amnesia of more than 24 hours. One person fell more than six meters, another was hit by a car, and another crashed their car. One year after injury all injured persons had resumed most activities with some residual effects. This outcome would be described as 'good recovery' according to the Glasgow Outcome Scale (Jennett \& Bond 1975).

\section{Figure 2: Family cases ( ${ }^{\text {family member recruited to the study) }}$}

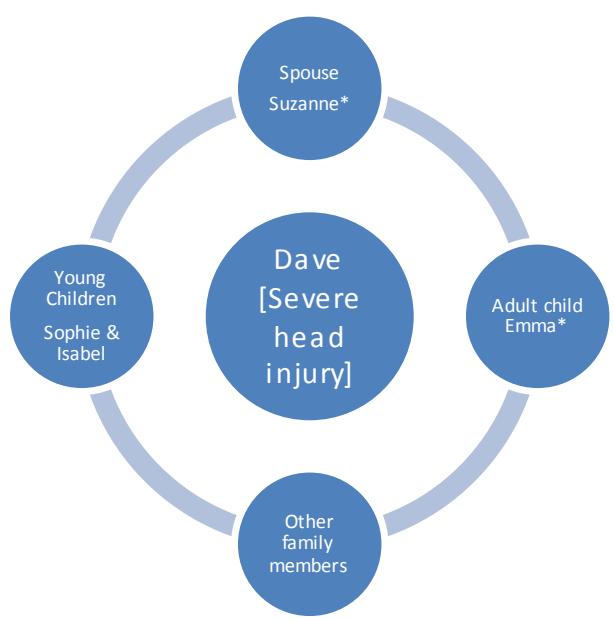

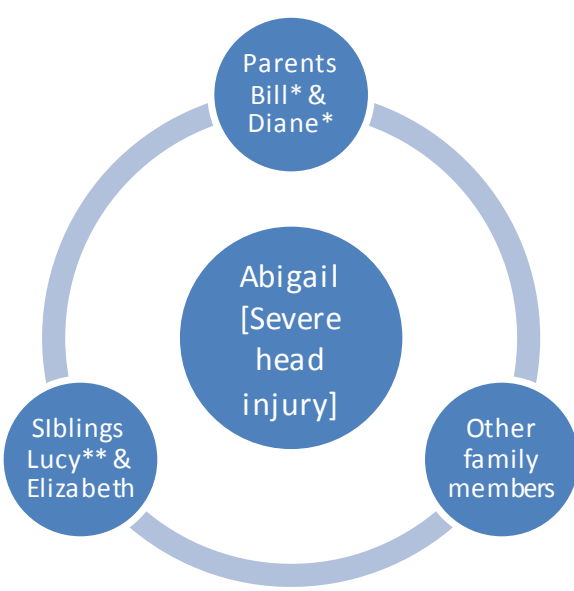

** Lucy withdrew from the study before the final interview.

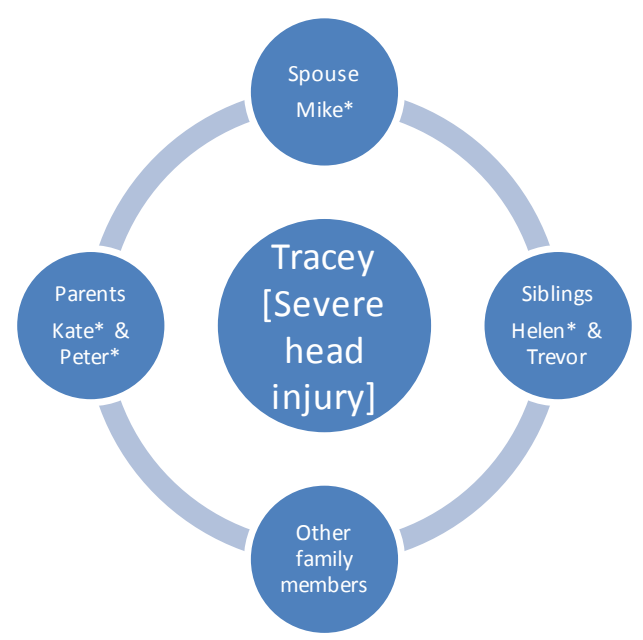


The between case analysis revealed a series of related narrative devices that illustrated the meaning attached to the stories of head injury told by non-injured family members. Five interrelated narrative threads were identified: trauma, recovery, autobiographical, suffering and family.

\section{Trauma narratives}

Family members represented trauma by talking specifically about the events that they had witnessed. The reason trauma made such an impact on the analysis was for its ability to act as a catalyst for crisis and distress. Embedded within the accounts of such crisis was raw emotion and desperate attempts by family members to make sense of the events that were unfolding before them. Without exception all family members experienced some level of fear, helplessness, and/or horror.

Diane [T1] "...he was crying... he was sobbing... and I think, I didn't, I just ... in-between times I tried to sleep... but... I think we only had about fifteen, ten minutes where we probably closed our eyes... 'causel couldn't stop seeing her...and l just, we'd seen her at the hospital and she'd looked awfulthen with the neck brace on and...[...]... they'd taped her eyes down with er...and she'd got all herglitter eye shadow on, and the doctor's like 'yes I couldn't remove it!'...[laughs]...oh dear..."

Helen [T1] "But through the intensive care... with the otherfamilies... and you watch other people disappear because theirfamilies... the person their looking after's... not made it... that's quite upsetting to watch... other families fall apart... and one of the things that really upset me... you can hear them telling the families in the next room... you can't actually hear them say it... butyou can kind of hear through the wall the responses... that was just awful..."

Peter [T1] "And just that one word... vegetative state... and you thought... oh hell... and we looked at each other... and your heart sank without a doubt... you know... you think... have we done her any justice like... have we got her life saved to be a vegetable... and you think god... what have we done... you know have we... has technology condemned her to... something worse than hell for the future... have we... have we done the wrong thing..."

Most of the trauma narratives were situated within the first interviews and represented the immediate impact of head injury. These narratives lacked the temporal features of a full narrative and seemed to exist within the 'incessant present' (Frank (1995) p.99). These fragments of narrative illustrate the origins of dismay, fear and horror that families were exposed to.

\section{Recovery narratives}

Recovery narratives traced the chronological features of the injured person's attainment of physical health. As such these were largely progressive in nature as the injured person moved towards the valued goal of return to their pre-injury state.

Peter [T2] "No... because once she woke up and started talking... erm... she... she was... almost instantly back to... to her normal, normal self although she was obviously sort of... you know only just capable of talking and... just... you know... hermanner and the way she's you know... talking and speak, speaking to people... it hasn't changed... it's just... it was wonderful to know... it was... it was our Tracey that was back and not... a half, a half something of a Tracey that was back..."

However threatening this narrative of recovery was the perception of change. In the recovery narratives family members grappled with the understanding that people who sustain head injuries often change in unexpected ways, and within the narratives of good physical recovery, change was often ambiguous, hard to quantify or measure.

Diane [T3] "I said, I've said to her before you know... do you think this is what you were like before or... or is this something, 'oh yes[!] she says, it was probably what I was like beforehand'... er... [pause]... she was worried she was going to wash away on holiday [said very quietly]... she'd gota 
li-lo... and I said to her she could sunbathe in the water... and er... the bay... the beach we'd gone to was really calm... and you had to walk a long way out... [laughs]... she thought she might wash away... so she stayed nearby which was nice... I suppose"

Suzanne [T3] "that's when we sort of find that... under stress he doesn'tcope as... as well as before... because he's sort of, sort of a calm person and... he would just deal with it you know really well... I think now he just gets really vocal and... sometimes you know if you walk into his office and you say something he just... BURST... or he snaps or he slams or he... breaks or... that's something that you know... he never used to do before..."

Where present this discourse of change was powerful and seemed to devalue the recovery achieved. Family members found it difficult to engage in these conversations explicitly without also emphasising their remarkable recovery.

\section{Autobiographicalnarratives}

Autobiographical narratives explored the family member's sense of self. Through the re-telling of their story family members showed how the experience of illness from a non-patient perspective was a critical life event. Family members embarked on a journey to make sense of what they were exposed to. Normal life was suspended as they became submerged in a new life that called for a renegotiation of roles and responsibilities. For one family member the importance of this life event was emphasised through the friends he had made during his wife's hospitalisation.

Mike [T3] "Erm... but that's a question I always ask myself... whether I'd go through it again... and, and we... we've, you know... the outcome's been so good and we've made such good... friends... or me I, in particular have made a few really close friends... that... will... keep, you know, we'll probably only contact each otheronce every two months... but we'll keep in contact for the rest of our life...you know there was... several people out of that... out of that relative's room... that... I wouldn't ever want to lose as friends and I'd never of met unless it happened... erm... and... some of them weren't so lucky and their... partners or... sons or daughters didn't... make it... but we keep in contact... and it's almost like a... it's almost like a secret club if you like... it's you know... if you don't know the secret knock you can't come in... and, and there's not many people in the world that have been through... what... the people that in that room go through... erm"

The experience of illness from a non-patient perspective demands revision of certain taken for granted attributes of character. The consequence of this was a form of biographical revision as the experience of head injury left an imprint on the lives of the non-injured members. However the narrative effect often went unnoticed or unappreciated by the injured person because they were not actively present due to coma, sedation or confusion.

\section{Suffering Narratives}

Narratives of suffering represented a longer-term accumulation of subjective loss and change. As the sharp edges of trauma dulled over time there remained a presence of pain and distress manifesting in some family members' accounts. This pain and distress were less immediate, more gradual and the effects endured.

Suzanne [T3] "It has changed... the whole family... well I feel I had my life before and after I've got an existence... I exist... [laughs]... well I can't say that the children er... but there was my life before... and now I'm just sort of... surviving... but I'm not... I don't feell can be happy hundred per cent as I was before... [...]... but as a family... [exhale]... yeah we feel... what's the word... harmed I suppose, it's scarred... mmm ... that's something that... you know... we'll remember always... it's changed, changed everyone... especially [our daughter]... you know it just, you know she... cries... and I don't know... she only little, poor thing... it's not fair... [cough]... yeah very scarred..."

Dianne [T2] "...I've had to fight all the time... and it's nothing majorly wrong with her... that she's gotover the accident... there's no thanks to them... I don't think so really... and to think my GP is 
the head of the... the practice... and he's telling me every single complaint that she had, and it was on the list of allergies... was a viral infection... I could not get over it... I just... I just could not get over it, even when I said she's covered in a red rash... he couldn't, he couldn't even accept that it could be an allergy to her medication..."

Although not present in all family members' accounts it was important to understand how the accumulation of subjective loss, pain and distress led to enduring suffering over time. A feature of much of the suffering was 'living through' and as such these stories were very much of the moment. Suffering frequently included the hallmarks of a regressive narrative as family members moved away from positive representations of the future and reduced their capacity to look forward, preferring to locate themselves, and their narrative, in the difficult present.

\section{Family narratives}

Family narratives explored the evolution of the family system. As such family members aligned their narratives to represent their family in the past, how they were functioning in the present and what they predicted the lasting effects on the family would be.

Emma [T1] "...but yeah I was saying to the guys at work! [laughs]... like oh erm...I was just joking saying actually it's brought me and Suzanne and the girls really close together... but if anything my Dad's been a bit left out on that 'cause... [laughs] ... he was just asleep for a few weeks and wakes up! [laughs] ... kind of... where we've all being kind of... grouped together, I guess, he wasn't actually really a part of that. That's a bit odd really isn't it? You'd think that he'd wake up and you'd feel really close to him or something, well no...he was just undersedation and then being a weirdo [...] so... yeah! [laughs] itfeels like we had a crisis and he wasn't around and we dealt with it... but he's not kind of benefited from all the bonding that gone on!... laughs]..."

Diane [T3] "...I know I can write... reams and reams... about how I feel because... the police were wanting Abby to write erm... a statement about how she felt... about the accident and... and Abby... couldn't put it into words really... she's like 'well I don't know how I feel... I don't remember it'... and I said 'well I can write it [!]' it's like schuch, schuch, schuch... [mimicking writing]... essay done here you go... [laughs]... and she's like 'oh'... I said yea h because... it's completely changed... everything... how it was... yourfuture... everything how we were looking forward to... life... on... you know... as life was going to be a completely different world to what it is now... and we just had to kind of like... all of a sudden go... it's like a bump [slaps hands]... stop... and then it's like... this pond of ripples it's like... just coming out and we're having to... to just get used to the idea..."

Head injury brought taken for granted relationships back into focus. Opportunities were real ised for new relationships to be forged in all families, but equally some relationships deteriorated. There was a sense that to feel closer was underpinned by a mutual respect, empathy, and understanding. The ability to communicate and openly discuss issues was another valued characteristic in several accounts. These enhanced relationships were often interpreted by family members as the primary way that positive meaning could be taken from the experience.

\section{DISCUSSION}

The analysis revealed five interrelated narratives that emphasised that the first year post-injury was a turbulent time of constant renegotiation.

Riessman (2008) suggests that stories emerge from ruptures in our everyday lives. Trauma narratives served to represent these ruptures and bring to mind the devastation left in their path. 'Broken' narratives such as these find some alignment with the chaos narratives identified by Frank (1995). Stories of this kind are considered chaotic in nature because of the absence of narrative order. Storytellers are thought to lack the metaphorical distance to facilitate self-reflection and the process of sense-making. Being unable to make sense of such events causes us to question the 
taken-for-granted aspects of our lives. At this point there can be deep despair or immense opportunity for change.

Many of the autobiographical narratives demonstrated features that Bury (2001) labelled 'moral narratives' where 'people are more able to identify more clearly their own personal values and sense of self-hood' (p.277). As such the theory of post-traumatic growth (Tedeschi and Calhoun 1996) is useful when considering the broad benefits that sometimes accompanied the process of meaning making and pursuit of purpose. Tedeschi and Calhoun (1996) identified three categories that were all present within the data: 'changes in self-perception, changes in interpersonal relationships, and a changed philosophy of life' (p.456). These features of a narrative can bring about a sense of benefit and purpose to traumatic events and illness.

Recovery narratives grappled with the understanding that people who sustain head injuries often change. Change is well established within lay and professional discourse regarding head injury and a feature of seminal TBI literature (Lezak 1978, 1986, 1988). However, examining narratives reveals the complex processes involved in the judgement of pre- and post-injury change. Change is not a one-dimensional outcome nor is it an endpoint within the recovery journey, a stage to be reached and then accepted and adjusted to. The findings of this study revealed that for at least a year after injury family members vacillated between aspects of the brain injured person that stayed the same, and aspects that were enhanced, subdued, and sometimes changed. Acknowledging and engaging with these co-existing perceptions may be a useful way of working with families post-injury.

In this research, suffering narratives contained some of the features of the kind of chaos narrative that dislocates the future from the present (Frank 1995). However the interpretation also resonated with the fracturing and enduring story lines that Brown and Addington-Hall (2008) identified in the stories of patients with motor neurone disease. For example:

'The enduring storyline tells us about quiet suffering [...]. Enduring was a way to live through an unwelcome and difficult situation' (p.204).

'The fracturing narrative tells of loss, breakdown of self, fear of the future, denial of reality and living in a surreal notion of time' (p.205)

Although trauma narratives were identified in all family members' accounts, narratives of suffering were reserved for the few. The effect of not sharing these narratives was further isolation and separation. Charmaz (1999) identified that in people with chronicillness stories of suffering represented 'loss of control, loss of certainty and loss of an anticipated future' (p.366). Although not suffering from illness themselves, non-injured family members displayed many of these features within their narratives. The findings of this study al so suggest that the long-term effects of hypothetical narratives that represent 'what could have been' were of ten afforded as much status as 'what actually happened'.

Family narratives find some resonance with family systems theory that states changes occuring to one person necessitate changes in others (Maitz \& Sachs 1995, Walker \& Akister 2004). These changes represent the ebb and flow of the family system that draws in during crisis (as family members come together to deal with the presenting situation) and moves out again once crisis has resolved. Common models of family adaptation post-TBI include Lezak (1986), Kosciulek et al. (1993), Degeneffe (2001) and Powell (2004). Models often include stages of denial and unrealistic expectations as features of the early experience, developing into anxiety, guilt and despair with a final phase of sorrow and mourning with the subsequent need for role reorganisation (Verhaeghe et al. 2005). However these models tend to reflect adjustment as a process that is reactive to head injury in isolation. Whilst it is essential that we understand these reactions it is al so a constraining view to think that the only process involved is in response to the injured person and their needs.

At the beginning of this paper a 'ripple effect' was used as a metaphor for understanding the family in the context of head injury. In line with this suggestion family members recruited to this study had 
to find a way of living with the effects of head injury and re-stabilise the family system post-injury. This process of re-stabilising has been referred to as returning to equilibrium (Verhaeghe et al. 2005, Wongvatunyu \& Porter 2005, 2008a, 2008b). The ripple effect assumes the family is stable preinjury and is displaced by the head injury to a family member. Given the findings of this research, we might need to think of this metaphor in a slightly different way. A new metaphor, rain on water, suggests the family is a dynamicever-changing system with ripples created by all family members moving in both similar and divergent directions. The image of rain on water may therefore be a more useful representation of the family system responding to TBI (Figure 3 ).

Figure 3: images of a ripple effect and rain on water

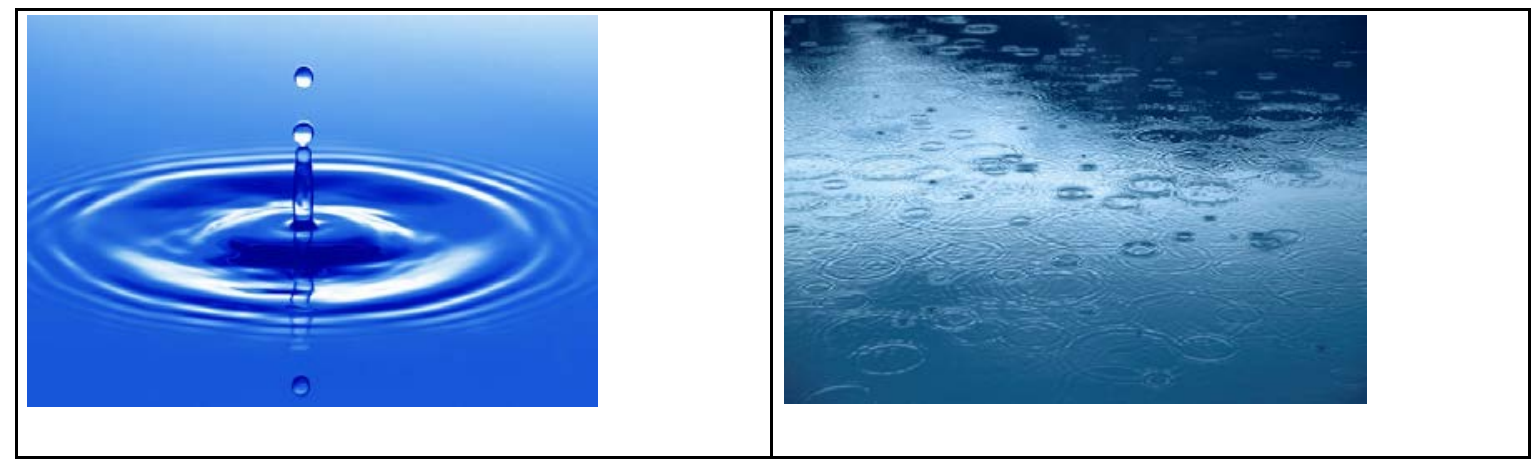

(images taken from Microsoft Word 2007 clip art)

\section{LIMITATIONS}

This was an in-depth case study that sought to understand the lives of a selective sample and therefore may not be generalizable to other families. In addition this selective sample meant there were family members who did not participate, including the injured person and children. How their stories might have contributed to answering the research question is unknown. Finally, despite this study having a longitudinal design one year is still a relatively short period of time. Therefore this study does not tell us about the continuing process of adaptation and change over a more extended period.

\section{CONCLUSION}

Although the aim of this study was not to generalise the findings to a larger population there are lessons to be learnt that may help to inform similar situations.

Although the experience of head injury will always remain with the injured person the story also belongs to the non-injured members who occupy the narrative especially in the early phases of recovery. Recommendations from this study are firstly that healthcare practitioners should understand why non-injured members become so embedded within the experience of a relative's head injury. Secondly, healthcare practitioners may be able to support recovery of the whole family by not invalidating or disregarding people's stories and the lasting effects of their experiences. Thirdly family members need help to understand that they too are changing as a result of their experiences. Therefore it would support family members if their story were heard and valued, both in its own right, and as part of the patient's journey through recovery. Finally, injured and noninjured family members' stories may be the same or different. Where stories are different there may be an opportunity to help families share their stories to support the whole family to come to terms with the effects. Alternatively it may help family members to identify narratives that can never be shared and be assisted to find ways to reconnect their narratives in the future. 
This study has shown the importance of listening to people's stories and understanding their journeys irrespective of the injured person's outcome. This study provides an opportunity to significantly shift the focus of future research and practice by raising the profile of narratives and by supporting practitioners to consider narratives within every day clinical practice. In doing so, care provision for the support needs of the whole family may be more effective. 
References

Anderson MI, Parmenter TR \& Mok M (2002) The relationship between neurobehavioural problems of severe traumatic brain injury (TBI), family functioning and the psychological well being of the spouse/caregiver: Path model analysis. Brain Injury 16(9), 743-757.

Appleton JV (2002) Critiquing approaches to case study design for a constructivist inquiry. Qualitative Research Journa/2(2), 80-97.

Bingley AF, Thomas C, Brown J, Reeve J \& Payne S (2008) Developing narrative research in supportive and palliative care: the focus on illness narratives. Palliative Medicine 22(5), 653-8.

Blake H (2008) Caregiver stress in traumatic brain injury. International Journal of Therapy \& Rehabilitation 15(6), 263-271.

Brooks N, Campsie L, Symington C, Beattie A \& McKinlay W (1986) The five year outcome of severe blunt head injury: a relative's view. Journal of Neurology, Neurosurgery, and Psychiatry 49(7), 764-70.

Brooks N, Campsie L, Symington C, Beattie A \& McKinlay W (1987) The effects of severe head injury on patient and relative within seven years of injury. Journal of Head Trauma Rehabilitation 2(3), 1-13.

Brown J \& Addington-Hall J (2008) How people with motor neurone disease talk about living with their illness: a narrative study. Journal of Advanced Nursing 62(2), 200-8.

Bury M (2001) IIIness narratives: fact or fiction? Sociology of Health \& Illness 23(3), 263-285.

Carnes SL \& Quinn WH (2005) Family Adaptation to Brain Injury: Coping and Psychological Distress. Families, Systems, \& Health 23(2), 186-203.

Charmaz K (1999) Stories of suffering: Subjective tales and research narratives. Qualitative Health Research 9(3), 362-382.

Creswell JW (2007) Qualitative inquiry \& research design: choosing among five approaches. (2nd edn) Sage Publications, Thousand Oaks.

Degeneffe CE (2001) Family caregiving and traumatic brain injury. Health \& Social Work 26(4), 25768.

DegeneffeCE \& Olney MF (2008) Future concerns of adult siblings of persons with traumatic brain injury. Rehabilitation Counseling Bulletin 51(4), 240-250.

Duff D (2006) Family impact and influence following severe traumatic brain injury. Axone 27(2), 9-23.

Ellis-Hill C, Payne S \& Ward C (2008) Using stroke to explore the life thread model: an alternative approach to understanding rehabilitation following an acquired disability. Disability and Rehabilitation 30(2), 150-9.

Frank A (1995) The Wounded Storyteller: Body, illness and ethics. The University of Chicago Press, Chicago.

Gan C, Campbell KA, Gemeinhardt M\& McFadden GT (2006) Predictors of family system functioning after brain injury. Brain Injury 20(6), 587-600.

Gergen K \& Gergen M (1983) Narratives of the self IN: Sarbin TR and Scheibe KE(eds) Studies in Social identity. Praeger, New York, pp. 254-273.

Jennett B \& Bond M (1975) Assessment of outcome after severe brain damage. Lancet 1(7905), 4804.

KosciulekJF, McCubbin MA \& McCubbin HI (1993) A theoretical framework for family adaptation to head injury. Journal of Rehabilitation 59(3), 40-45.

Lezak MD (1978) Living with the characterologically altered brain injured patient. Journal of Clinical Psychiatry 39(7), 592-8.

Lezak MD (1986) Psychological implications of traumatic brain damage for the patient's family. Rehabilitation Psychology 31(4), 241-250.

Lezak MD (1988) Brain damage is a family affair. Journal of Clinicaland Experimental Neuropsychology 10(1), 111-23.

Livingston MG, Brooks DN \& Bond MR (1985) Three months after severe head injury: psychiatric and social impact on relatives. Journal of Neurology, Neurosurgery, and Psychiatry 48(9), 870-5. 
Maitz EA \& Sachs PR (1995) Treating families of individuals with traumatic brain injury from a family systems perspective. Journal of Head Trauma Rehabilitation 10(2), 1-11.

Merriam SB (1998) Qualitative research and case study applications in education. (Revised edn), Jossey-Bass, San Francisco.

Miles MB \& Huberman AM (1994) Qualitative data analysis : an expanded sourcebook. (2nd edn) Sage Publications, London.

MishlerEG (1995) Models of narrative analysis: a typology. Journal of Narrative \& Life History 5(2), 87-123.

Nabors N, Seacat J \& Rosenthal M (2002) Predictors of caregiver burden following traumatic brain injury. Brain Injury 16(12), 1039-1050.

Powell TJ (2004) Head injury: a practical guide. (2nd edn) Speechmark, Bicester

Riessman CK (2008) Narrative methods for the human sciences. Sage Publications, Los Angeles.

Riessman CK and Quinney L (2005) Narrative in Social Work: A Critical Review. Qualitative Social Work 4(4), 391-412.

Schönberger M, Ponsford J, Olver J \& Ponsford M (2010) A longitudinal study of family functioning after TBI and relatives' emotional status. Neuropsychological Rehabilitation 20(6), 813-829.

Sparkes AC \& Smith B (2008) Narrative Constructionist Inquiry IN: Holstein JA and Gubrium JF (eds) Handbook of Constructionist Research. Guildford Press, New York, pp. 295-315.

Stake RE (2005) Qualitative Case Studies IN: Denzin NK and Lincoln YS (eds) The Sage Handbook of Qualitative Research. (3rd edn) Sage Publications, London, pp. 443-466.

Teasdale GM (1995) Head injury. Journal of Neurology, Neurosurgery, and Psychiatry 58(5):526-39

Tedeschi RG \& Calhoun LG (1996) The Posttraumatic Growth Inventory: measuring the positive legacy of trauma. Journal of Traumatic Stress 9(3), 455-71.

Verhaeghe S, Defloor T\& Grypdonck M (2005) Stress and coping among families of patients with traumatic brain injury: a review of the literature. Journal of Clinical Nursing 14(8), 1004-12.

WalkerS \& AkisterJ (2004) Applying family therapy: a guide for caring professionals in the community. Russell House, Lyme Regis.

Wengraf T \& Chamberlayne P (2006) Interviewing for life-histories, lived situations and personal experience: The Biographic-Narrative Interpretive Method(BNIM). Shortest Short Guide to $B N I M$ interviewing and interpretation. Un-published.

Whiffin CJ (2012) A study of family transistion in the first year post-head injury: perspectives of the non-injured members. Unpublished PhD thesis, Southampton University.

Whiffin CJ, Bailey C, Ellis-Hill C, \& Jarrett N (2014) Challenges and solutions during analysis in a longitudinal narrative case study. Nurse Researcher 21(4), 20-26.

Wongvatunyu S \& Porter EJ (2005) Mothers' experience of hel ping young adults with traumatic brain injury. Journal of Nursing Scholarship 37(1), 48-55.

Wongvatunyu S \& Porter EJ (2008a) Changes in family life perceived by mothers of young adult TBI survivors. Journal of Family Nursing 14(3), 314-32.

Wongvatunyu S \& Porter EJ (2008b) Helping young adult children with traumatic brain injury: the life-world of mothers. Qualitative Health Research 18(8), 1062-74.

Wright LM \& Leahey M (2009) Nurses and familes: a guide to family assessment and intervention. (5th edn) F.A. Davis, Philadelphia.

Wood RL, Liossi C \& Wood L (2005) The impact of head injury neurobehavioural sequelae on personal relationships: preliminary findings. Brain Injury 19(10), 845-51. 